\title{
Metilen Mavisinin Doğal Kil Üzerine Adsorpsiyonu
}

\author{
Adsorption of Methylene Blue onto Natural Clay
}

\begin{abstract}
Serkan BAYAR*
Atatürk Üniversitesi, Mühendislik Fakültesi, Çevre Mühendisliği Bölümü, 25240, Erzurum

• Geliş tarihi / Received: 17.10.2017 • Düzeltilerek geliş tarihi / Received in revised form: $14.02 .2018 \quad$ • Kabul tarihi / Accepted: 19.03 .2018

$\ddot{O} z$

Bu çalışmada, kesikli sistem adsorpsiyon prosesi ile sentetik olarak hazırlanan sulu çözeltilerden metilen mavisi (MM) boyar maddesinin uzaklaştırılmasında Erzurum ili Narman ilçesinden temin edilen doğal kilin kullanılabilirliği araştırılmıştır. Deneysel parametreler olarak; pH (3.0 - 8.0 aralığı), karıștırma hızı (100 devir/dakika - 400 devir/dakika aralı̆̆ı), başlangıç boyar madde konsantrasyonu $\left(25 \mathrm{mg} \cdot \mathrm{L}^{-1}-500 \mathrm{mgL}^{-1}\right.$ aralığı), adsorban dozaj1 $\left(0.025 \mathrm{~g} 100 \mathrm{~mL}^{-1}-\right.$ 0.100 g. $100 \mathrm{~mL}^{-1}$ aralığı $)$ ve $\mathrm{NaCl}$ konsantrasyonu $(0 \mathrm{mM}-0.001 \mathrm{mM}$ aralı̆̆ı) seçilmiştir. Çalışmalarda adsorpsiyon veriminin artan başlangıç MM konsantrasyonu, $\mathrm{pH}$ ve karıştırma hızı ile arttığı, $\mathrm{NaCl}$ konsantrasyonu ve adsorban dozajı ile azaldığı tespit edilmiştir. Çalışmalar sonucunda doğal kilin en yüksek adsorpsiyon kapasitesinin $25^{\circ} \mathrm{C}^{\prime}$ de, 300 devir/dakika karıştırma hızında, çözelti doğal $\mathrm{pH}$ değerinde ve $500 \mathrm{mg} \cdot \mathrm{L}^{-1} \mathrm{MM}$ konsantrasyonunda $338.15 \mathrm{mg} . \mathrm{g}^{-}$ ${ }^{1}$ olduğu tespit edilmiştir.
\end{abstract}

Anahtar kelimeler: Adsorpsiyon, Kil, Kimyasal Oksijen İhtiyacı, Metilen Mavisi

\begin{abstract}
In this study, the utilization of natural clay obtained from the Narman district of Erzurum province was investigated in the removal of methylene blue (MB) from synthetically prepared aqueous solutions by batch adsorption process. As experimental parameters; the influences of initial pH of solution (from 3.0 to 8.0), stirring speed (from 100 to $400 \mathrm{rpm}$ ), initial dyestuff concentration (from $25 \mathrm{mg} . \mathrm{L}^{-1}$ to $500 \mathrm{mg} \cdot \mathrm{L}^{-1}$ ), adsorbent dosage (from $0.025 \mathrm{~g} .100 \mathrm{~mL} \mathrm{~L}^{-1}$ to 0.100 g.100 $\mathrm{mL}^{-1}$ ) and $\mathrm{NaCl}$ concentration (from 0 to $0.001 \mathrm{mM}$ ) were selected. It was established that adsorption amount increased with increasing $\mathrm{pH}$, dye concentration and stirring speed, but decreased with increased ionic strength and adsorbent dosage. As a result of working, the highest adsorption capacity of natural clay was observed as $338.15 \mathrm{mg} . \mathrm{g}$ ${ }^{I}$ at $25^{\circ} \mathrm{C}$, at a stirring speed of $300 \mathrm{rpm}$, at a solution of natural pH and at a initial MB concentration of $500 \mathrm{mg} . \mathrm{L}^{-1}$.
\end{abstract}

Keywords: Adsorption, Clay, Chemical Oxygen Demand, Methylene Blue 


\section{Giriş}

Tekstil endüstrisi, yüksek kirlilik yükü ve atık su miktarı, çözünmüş madde konsantrasyonu ve değişik yapıda boyar maddeler içeren çeşitli üretim proseslerine sahip sanayi dallarından birisidir. Tekstil endüstrisi atık suları çoğunlukla yüksek konsantrasyonlarda organik ve inorganik kimyasallar barındırır ve bu atık sular yüksek konsantrasyonlarda Kimyasal Oksijen İhtiyac1 (KOI), Toplam Organik Karbon (TOK) ve renk içerirler. Dünya genelinde üretilen boyar maddelerin yıllık yaklaşık \%20'si atık sulara verilmektedir. Tekstil atık sularındaki bu boyar maddeler; hem klasik arıtma sistemlerine direnç göstermeleri hem de boyar maddelerin hidroliz olmaları sonucunda toksik ve kanserojenik yan ürünler üretmeleri nedeniyle önemli bir çevre kirliliği problemi haline gelmiştir. Kullanılan boyar maddeler belirli dalga boylarında 1 şık için kuvvetli absorpsiyon kabiliyetine sahip olduklarından, alıcı ortamlardaki 1şık geçirgenliğini azaltarak, bitkilerin fotosentez hızlarını düşürmekte ve dolayısıyla doğal yoldan oksijen üretiminin düşmesine neden olmaktadırlar (Y1lmaz, 2009).

Günümüzde tekstil endüstrisinden kaynaklanan atık suların arıtılması için, membran filtrasyonu (Molinari vd., 2004; Zhu vd., 2013), ileri oksidasyon (Panizza ve Cerisola, 2009), ozonlama (Van Leeuwen vd., 2009) elektrokoagülasyon (Aoudj vd., 2010; Y1lmaz, 2012), koagülasyon/flokülasyon (Moghaddam vd., 2010; Man vd., 2012), adsorpsiyon (Mahmoodi, 2011; Habte vd., 2014) ve biosorpsiyon (Somasekhara Reddy vd., 2012) yaygin olarak kullanılan arıtma prosesleridir.

Adsorpsiyon bir fazda bulunan iyon ya da moleküllerin, bir diğer fazın yüzeyinde yoğunlaşması ve konsantre olması işlemi olarak tanımlanabilir. Biriken maddeye "adsorbat", adsorplayan maddeye de "adsorbent" ya da "adsorban" denir. Adsorpsiyon; s1v1-s1v1, siv1-gaz, sıv1-kat1 ya da gaz-katı gibi iki faz arasında oluşur. Bu iki fazı ayıran yüzeyler 'ara yüzey' olarak isimlendirilir. Adsorpsiyon prosesinde adsorban olarak kullanılacak maddeler; ucuz ve kolay elde edilebilir olmalı, zehirli olmamalı, geniş yüzey alanına sahip olmalı, suda çözünmemeli ve yeniden kullanılabilir olmalıdır (Özdeş vd., 2009). Adsorpsiyon prosesinde en yaygın olarak kullanılan adsorban madde aktif karbon olmakla birlikte, aktif karbonun pahalı olması ve geri kazanımının ilave maliyet getirmesi gibi dezavantajları da bulunmaktadır. Son yıllarda düşük maliyetli ve doğal adsorbanların kullanımı da yaygınlaşmıştır (Çulcu, 2015). Adsorpsiyon prosesinde; polimerler (Kim ve Guiochon, 2005), pomza taşı (Veliev vd., 2006), kil (Veli ve Alyüz, 2007), bentonit (Bulut vd., 2008) ve aktif karbon (Khaled vd., 2009; Bangash ve Alam, 2009; Schimmel vd., 2010) yaygın olarak kullanılan adsorbanlardan bazılarıdır.

$\mathrm{Bu}$ çalışmada, tekstil, deri ve kâğıt gibi endüstrilerde yaygın olarak kullanılan, sularda çok düşük konsantrasyonlarda bulunması halinde bile toksik etkilere sahip olan katyonik bir boyar madde olan metilen mavisinin (MM) sulu çözeltilerden uzaklaştırılma şartları araştırılmıştır. Adsorban olarak Erzurum ili Narman ilçesi havzasından temin edilmiş sarı renkli doğal kil kullanılmıştır. Çalışmalarda MM'nin doğal kil üzerine adsorpsiyonu $\mathrm{pH}$, karıştırma hızı, başlangıç MM konsantrasyonu, adsorban dozajı ve elektrolit konsantrasyonun etkisi incelenerek optimum koşullar belirlenmiştir.

\section{Materyal Metot}

\subsection{Kullanılan Adsorban ve Özellikleri}

Adsorpsiyon deneylerinde kullanılan doğal kil minerali, Erzurum ili Narman ilçesinden temin edilmiştir. Araziden getirilen doğal kil örnekleri etüvde $\left(105^{\circ} \mathrm{C}^{\prime} \mathrm{de}\right)$ kurutulduktan sonra öğütücüde (Los Angles Işınma aletinde) yeterli süre ögütülmüş̧ ve daha sonra ögütülmüş numunelerden gerekli miktar alınarak su ile karıştırılmış ve kil süspansiyonu hazırlanmıştır. Daha sonra hazırlanan kil süspansiyonu içindeki silt boyutundaki malzemeler Stokes yasasına göre yeterli süre (1 saat kadar) çöktürülmüş (Uzuner, 2005) ve çöken malzeme (silt) süspansiyondan uzaklaştırılmıştır. Kil numunesine yaptırılan XIşını Fraksiyonu (XRF) analiz sonuçlarından elde edilen kimyasal bileşenler Tablo 1'de verilmiştir.

Tablo 1. Kullanılan kil mineralinin kimyasal bileşimi

\begin{tabular}{ll}
\hline Kimyasal Bileşimi & Yüzde Miktar (\%) \\
\hline $\mathrm{Na}_{2} \mathrm{O}$ & 0.02 \\
$\mathrm{MgO}$ & 2.82 \\
$\mathrm{Al}_{2} \mathrm{O}_{3}$ & 20.67 \\
$\mathrm{SiO}_{2}$ & 53.28 \\
$\mathrm{~K}_{2} \mathrm{O}$ & 0.82 \\
$\mathrm{CaO}$ & 1.71 \\
$\mathrm{TiO}_{2}$ & 0.63 \\
$\mathrm{Fe}_{2} \mathrm{O}_{3}$ & 6.13 \\
$\mathrm{Limit}_{\mathrm{Oksijen} \text { İndeksi (LOI) }}$ & 14.00 \\
$\mathrm{SiO}_{2} / \mathrm{Al}_{2} \mathrm{O}_{3}$ & 2.57 \\
$\mathrm{SiO}_{2} / \mathrm{Fe} \mathrm{O}_{3}$ & 8.69 \\
$\mathrm{SiO}_{2} / \mathrm{MgO}$ & 18.89 \\
$\mathrm{SiO}_{2} / \mathrm{CaO}$ & 31.15 \\
\hline
\end{tabular}




\subsection{Kullanılan Boyar Madde}

Adsorbat olarak kullanılan MM'nin kimyasal formülü $\mathrm{C}_{16} \mathrm{H}_{18} \mathrm{CIN}_{3} \mathrm{~S}$ olup, $319.85 \mathrm{~g} \cdot \mathrm{mol}^{-1}$ molekül ağırlığına sahiptir. MM'nin molekül yapısı Şekil 1'de görülmektedir.<smiles>CN(C)c1ccc2nc3ccc(=[N+](C)C)cc-3sc2c1</smiles>

Şekil 1. MM'nin molekül yapısı

\subsection{Adsorpsiyon Çalışmaları}

Adsorpsiyon deneyleri $100 \mathrm{~mL}$ 'lik çalışma hacmine sahip erlenlerde yürütülmüştür. Sicaklık ve karıştırma hızının adsorpsiyon üzerine etkilerinin incelenmesinde, ayarlı Edmünd Bühler $\mathrm{GmbH}$ (KS-15) marka çalkalamalı inkübatör kullanılmıştır. Çalışmalar kesikli modda gerçekleştirilmiş olup, pH etkisinin incelenmesi dışındaki tüm çalışmalarda çözeltinin doğal pH değerinde $\left(100 \quad \mathrm{mg} . \mathrm{L}^{-1}\right.$ için $\left.\mathrm{pH} \approx 5.20\right)$ çalışılmıştır. MM çözeltilerinin başlangıç konsantrasyonları 25-500 mg.. $\mathrm{L}^{-1}$ aralığında değiştirilmiştir. Çözeltilerin pH's1 WTW multi 340 i marka pH-metre kullanılarak $1 \mathrm{~N} \mathrm{NaOH}$ ve $1 \mathrm{~N} \mathrm{HCl} \mathrm{çözeltileri} \mathrm{ile} \mathrm{ayarlanmıştır.}$

Kimyasal oksijen ihtiyac1 analizleri standart metotlarda (APHA, 1998) belirtilen kapalı sistem (reflux) yöntemine göre yapılmıştır. Doğal kilin adsorpsiyon kapasitesi ve KOİ giderim verimleri aşağıdaki kütle denkliği eşitlikleri kullanılarak hesaplanmıştır (Sapawe vd., 2013).

$$
\begin{aligned}
& \eta(\%)=\left(\frac{C_{0}-C_{t}}{C_{0}}\right) x 100 \\
& q_{t}=\frac{\left(C_{o}-C_{e}\right) * V}{m}
\end{aligned}
$$

Burada $q_{\mathrm{t}}\left(\mathrm{mg} \cdot \mathrm{g}^{-1}\right) ; t$ anında birim adsorban yüzeyinde tutunan KOİ miktarı, $C_{\mathrm{o}}$ ve $C_{\mathrm{t}}$; başlangıç ve $t$ anındaki MM konsantrasyonları (mg.L $\left.\mathrm{L}^{-1}\right), \quad V ;$ MM çözeltisinin hacmi (L), $m$; kullanılan doğal kil örneğinin kütlesi (g) ve $\eta ; \%$ KOİ giderim verimidir.

\section{Bulgular ve Tartışma}

\subsection{Başlangıç Çözelti pH'sının Etkisi}

Başlangıç çözelti pH'sı askıdaki partiküller üzerinde boyanın adsorpsiyonunu kontrol eden en önemli parametrelerden biridir (Doğan vd., 2004). MM'nin doğal kil örnekleri yüzeyinde KOİ adsorpsiyon verimi; $25{ }^{\circ} \mathrm{C}$ sicaklıkta, 300 devir/dakika (dev.dak ${ }^{-1}$ ) karıştırma hızında, 60 dakika denge süresinde ve $\mathrm{pH}$ değerleri 3.0; 4.0; $5.0 ; 6.0 ; \quad 7.0$ ve 8.0 olan çözeltiler için incelenmiştir. Elde edilen sonuçlar Şekil 2'de gösterilmiştir. Deneysel sonuçlardan başlangıç çözelti pH değerinin artmasıyla adsorpsiyon veriminde artma gözlenmiştir. pH 3.0'dan 8.0'a arttığında adsorpsiyon verimi de $188.1 \mathrm{mg}^{-1} \mathrm{~g}^{-1} \mathrm{den}$ $200.2 \mathrm{mg} \cdot \mathrm{g}^{-1}$ e yükselmiştir.

Adsorbanların yüzey yükünü çözelti pH'sı büyük ölçüde etkiler. Sulu çözeltide bulunan hidronyum ve hidroksil iyonları adsorban yüzeyine oldukça güçlü bir şekilde adsorbe olurlar. Bu nedenle diğer iyonların adsorpsiyonu çözelti $\mathrm{pH}$ değerinden etkilenir. $\mathrm{pH}$ değişimi adsorban yüzey aktif sitlerinde fonksiyonel grupların ayrışması yoluyla adsorpsiyon prosesini etkiler.

Asidik pH değerlerinde adsorbanın çevresi $\mathrm{H}_{3} \mathrm{O}^{+}$ iyonlarıyla çevrilmiş olup, adsorbanın yüzey fonksiyonel grupları pozitif yüklüdür (Gündoğdu, 2010). $\mathrm{H}_{3} \mathrm{O}^{+}$iyonlar1, elektrostatik itmeden dolay1 aynı yüke sahip $\mathrm{MM}$ katyonlarının adsorban yüzeyine yaklaşmasını engeller. $\mathrm{Bu}$ nedenle, katyonik formdaki MM'nin adsorpsiyon verimi asidik $\mathrm{pH}$ değerlerinde düşük olup, $\mathrm{pH}$ arttıkça artmaktadır.

Adsorpsiyon veriminin $\mathrm{pH}$ 'nın yükselmesiyle artmasının nedeni, $\mathrm{H}_{3} \mathrm{O}^{+}$iyonları ile katyonik formdaki MM'nin adsorban yüzeyindeki aktif bölgelere olan rekabetinin azalması ve ayrıca adsorban yüzeyindeki pozitif yükün azalmasıyla elektrostatik etkileşimin artması şeklinde açıklanabilir.

Benzer sonuçlar literatürde mevcuttur (Vučurović vd., 2012; Sözüdoğru vd., 2016). Ayrıca doğal kilin MM adsorpsiyon kapasitesi literatürde verilen diğer adsorbanlarla karşılaştırılmış ve bu değerler Tablo 2'de gösterilmiştir. 


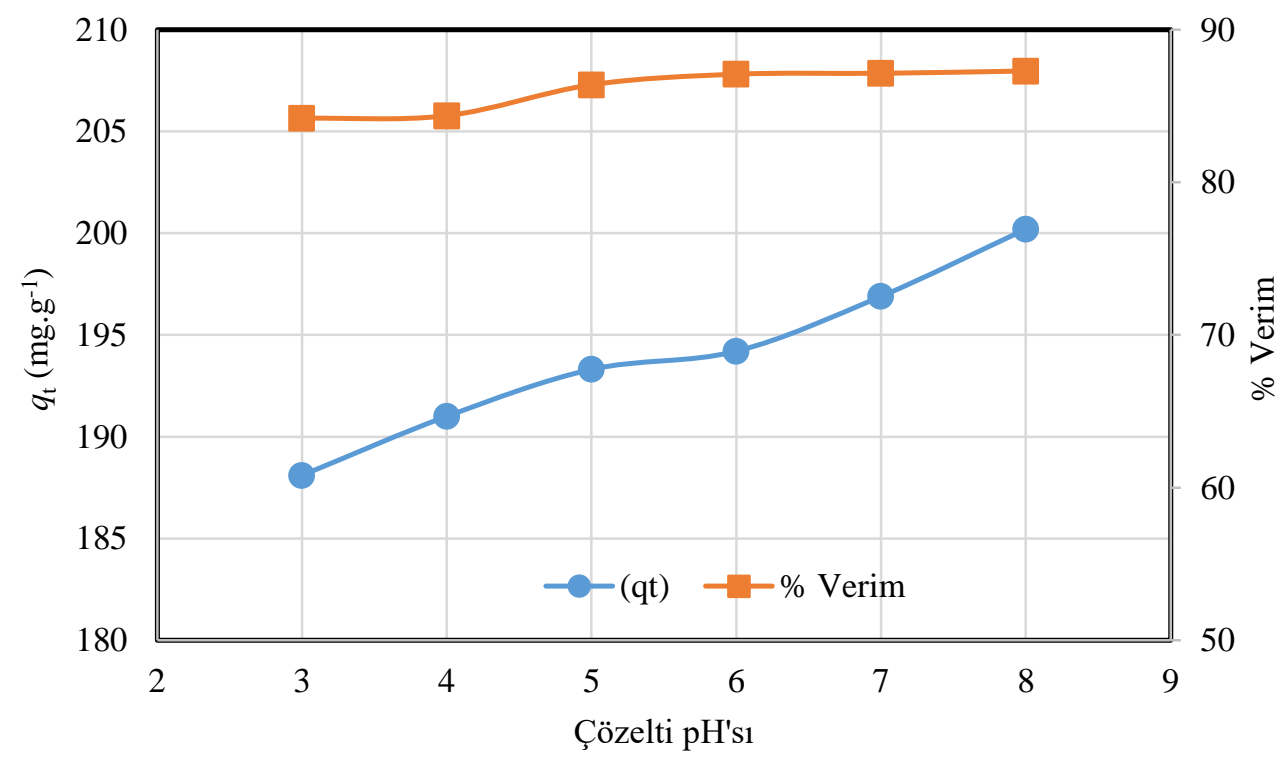

Şekil 2. Adsorpsiyon üzerine başlangıç çözelti pH'sının etkisi

Tablo 2. Kullanılan kil mineralinin $M M$ adsorpsiyon kapasitesinin literatürde verilen diğer adsorbanlarla karşılaştırılması

\begin{tabular}{lll}
\hline Adsorban & Adsorpsiyon kapasitesi $\left.\mathbf{( m g . g}^{-\mathbf{1}}\right)$ & Kaynak \\
\hline Kaolin & 52.76 & Mounia vd., 2018 \\
Kaolinit & 101.50 & Gao vd., 2016 \\
Kaolinit & 102.04 & Krishnan vd., 2015 \\
Sentezlenmiş Zeolit & 64.8 & Sapawe vd., 2013 \\
Şeker pancarı küspesi & 714.29 & Vučurović vd., 2012 \\
Doğal Zeolit & 19.92 & Han vd., 2009 \\
Montmorillonit & 289.12 & Almeida vd., 2009 \\
İllit Kili & 24.87 & Özdeş vd., 2009 \\
Kil & 58.20 & Gürses vd., 2006 \\
Limon Kabuğu & 29.0 & Kumar vd., 2006 \\
Uçucu Kül & 5.72 & Kumar vd., 2005 \\
Pirinç çeltiği & 40.58 & Vadivelan vd., 2005 \\
Doğal Kil & $\mathbf{3 3 8 . 1 5}$ & Bu çalışma \\
\hline
\end{tabular}

\subsection{Karıștırma hızının etkisi}

Karıştırma hızı, dış sınır tabakanın yapısını etkilediğinden dolayı adsorpsiyon prosesi için önemli bir parametredir. MM'nin doğal kil örnekleri yüzeyinde adsorpsiyon verimine karıştırma hızının etkisi; doğal pH, $25{ }^{\circ} \mathrm{C}$ sicaklıkta, 60 dakika denge süresinde, 0.075 g. $\mathrm{L}^{-1}$ adsorban miktarında, $100 \mathrm{mg} . \mathrm{L}^{-1}$ başlangıç boyar madde konsantrasyonunda, 100; 200; 300 ve 400 dev.dak ${ }^{-1}$ karıştırma hızlarında incelenmiştir.
Çalışma sonunda elde edilen veriler Şekil 3'de gösterilmiştir. Şekil 3'de görüleceği gibi karıştırma hızı arttıkça adsorpsiyon veriminde artış gözlenmiştir. Karıştırma hızı 100 dev.dak ${ }^{1}$, den 400 dev.dak ${ }^{-1}$ e arttığında adsorpsiyon verimi $150.67 \mathrm{mg} . \mathrm{g}^{-1}$, den $191.36 \mathrm{mg} \cdot \mathrm{g}^{-1}$ değerine ulaşmıştır. Bu sonuç; artan karıştırma hızıyla kil çevresindeki akışkan film kalınlığının azalması ve buna bağlı olarak adsorpsiyon veriminin artmas1 şeklinde açıklanabilir. Literatürde benzer sonuçlar mevcuttur (Crini vd., 2007; Sözüdoğru vd., 2016). 


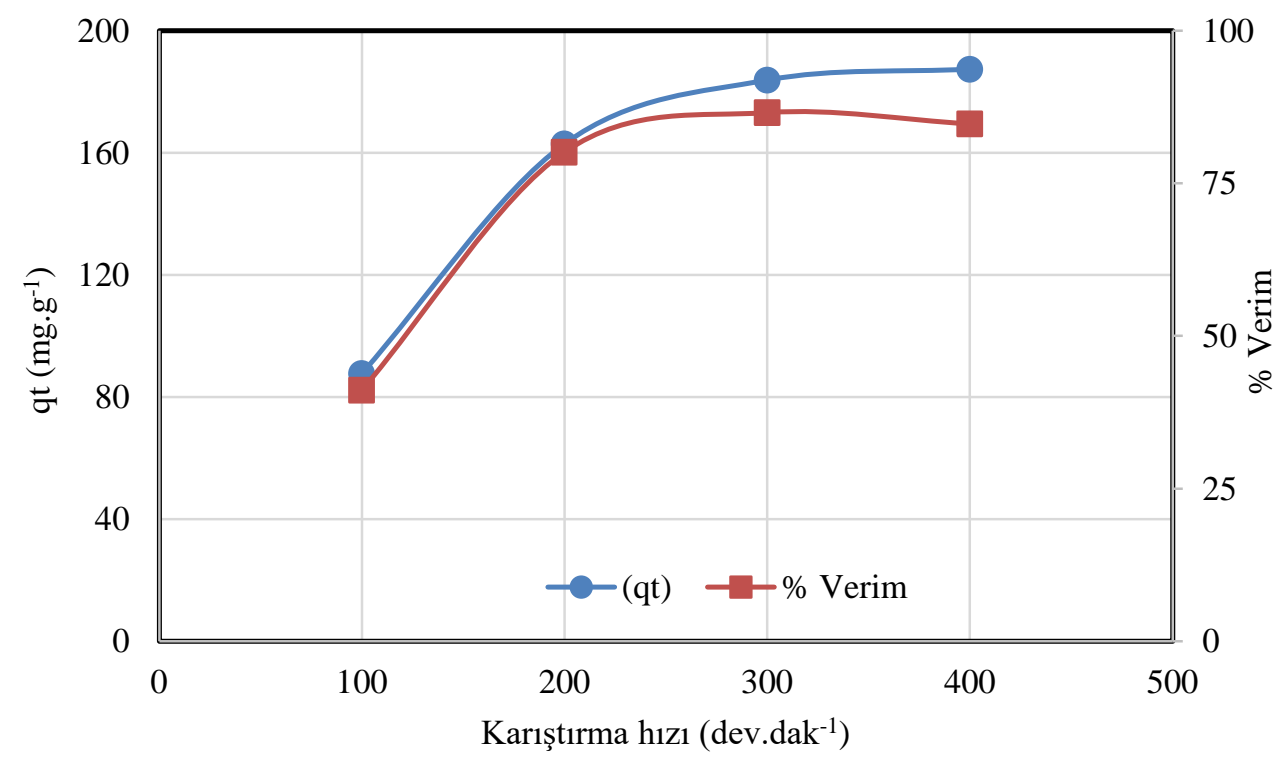

Şekil 3. Adsorpsiyon üzerine karıştırma hızının etkisi

\subsection{Başlangıç boyar madde konsantrasyonunun etkisi}

Adsorpsiyon üzerine başlangıç $\mathrm{MM}$ konsantrasyonunun etkisi; 25; 50; 100; 250 ve 500 mg. $\mathrm{L}^{-1}$ konsantrasyon aralıklarında, $25{ }^{\circ} \mathrm{C}$ 'de, 300

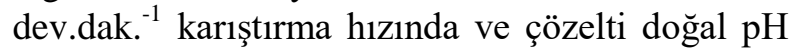
değerinde incelenmiştir. Çalışma sonunda elde edilen deneysel sonuçlar Şekil 4'de gösterilmiştir. Şekil 4 incelendiği zaman artan MM konsantrasyonu ile doğal kil yüzeyinde adsorplanan KOİ miktarında artış olduğu görülmektedir. Ayrıca başlangıç boyar madde konsantrasyonu arttıkça adsorpsiyon kapasitesi de artmaktadır (Vimonses vd., 2009). Başlangı̨̧ MM konsantrasyonu 25 mg. $\mathrm{L}^{-1}$ den $500 \mathrm{mg} . \mathrm{L}^{-1}$ ye artırıldığında birim adsorban başına adsorplanan KOİ değeri sırasıyla $45.53 \mathrm{mg} \cdot \mathrm{g}^{-1}$ dan $338.15 \mathrm{mg} \cdot \mathrm{g}^{-1}$ a yükselmiştir. KOİ giderim verimleri de $\% 74.32$ 'den $\% 32.61$ 'e düşmüştür. Sabit doğal kil konsantrasyonunda, başlangıç MM konsantrasyonun artışı, gram adsorban başına daha fazla MM adsorplanmasina neden olur. (MM konsantrasyonu çözelti ve katı faz arasında oluşacak kütle transferi için önemli bir itici güç olduğu için). Ayrıca doğal kil yüzeyindeki aktif bölgelerin doygunluğa ulaşmasından dolayı adsorpsiyon yüzdesi azalmaktadır (Özdeş vd., 2009).

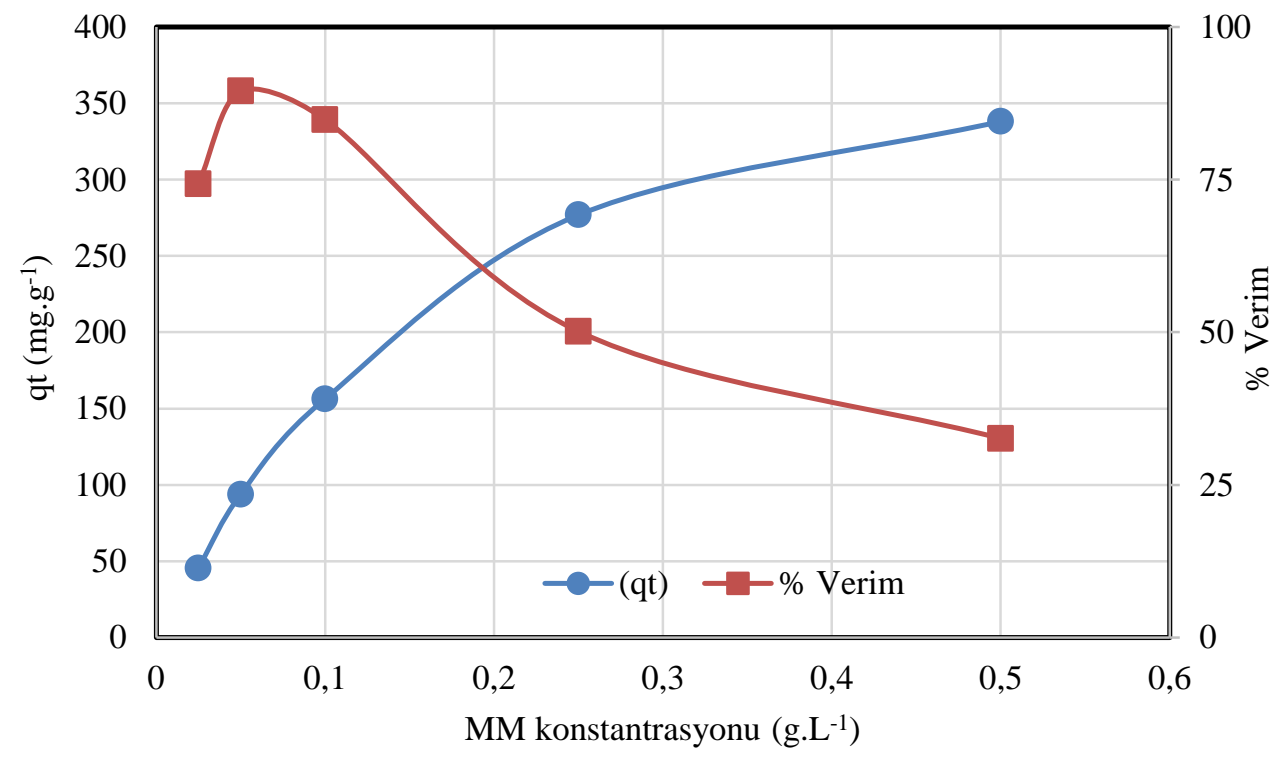

Şekil 4. Adsorpsiyon verimi üzerine başlangıç MM konsantrasyonunun etkisi 


\subsection{Adsorban miktarının etkisi}

Doğal kil mineralinin süspansiyon içerisindeki miktarının adsorpsiyon verimine etkisi; 0.025 ; $0.050 ; \quad 0.075$ ve $0.10 \quad$ g.. -1 $^{-1}$ lik kat1-sıv1 oranlarında, $\quad 25 \quad{ }^{\circ} \mathrm{C} \quad$ sicaklıkta, $100 \quad$ mg. $\mathrm{L}^{-1}$ başlangıç MM konsantrasyonunda, 300 dev.dak. ${ }^{-1}$ karıştırma hızında ve doğal pH'da incelenmiştir. Elde edilen sonuçlar Şekil 5'te grafik edilmiştir. Şekil 5'ten de görülebileceği gibi doğal kilin artan süspansiyon kat1-sıv1 oranı ile adsorpsiyon hız ve miktarı azalmıştır. Adsorban dozajı 0.025 g.L $\mathrm{L}^{-}$ ${ }^{1}$ den 0.1 g.. $L^{-1}$ ye arttırıldı ğında KOİ giderim verimi \%34.33'dan \%93.91'e artmaktadır ama adsorpsiyon verimi $230.08 \mathrm{mg} . \mathrm{g}^{-1}$, dan 126.85 $\mathrm{mg} \cdot \mathrm{g}^{-1}$ a azalmaktadır. Adsorpsiyon yoğunluğundaki bu azalış sorpsiyon prosesi boyunca doymamış artık sorpsiyon sitlerinin varlığıyla açıklanabilir (Varlikli vd., 2009; Vimonses vd., 2009).

\subsection{Elektrolit konsantrasyonunun etkisi}

Endüstriyel atık sular inorganik tuzlar gibi çeşitli katk1 maddeleri ile daima kirletildiği için boya çözeltilerinin adsorpsiyon niteliği üzerindeki bu iyonların etkilerinin incelenmesi önemlidir. $\mathrm{Bu}$ amaçla; $100 \mathrm{mg}$. $\mathrm{L}^{-1}$ konsantrasyonundaki $\mathrm{MM}$ çözeltileri ve 0.075 g. $\mathrm{L}^{-1}$ derişimindeki doğal kil süspansiyonlar1, $\quad 0.001 \quad \mathrm{mM} \quad-\quad 0.1 \quad \mathrm{mM}$ aralıklarındaki $\mathrm{NaCl}$ çözeltileriyle, 60 dakika, 300 dev.dak. ${ }^{-1}$ karıştırma hızında ve doğal pH'da muamele edilmiştir. Elde edilen veriler Şekil 6'da grafik edilmiştir.

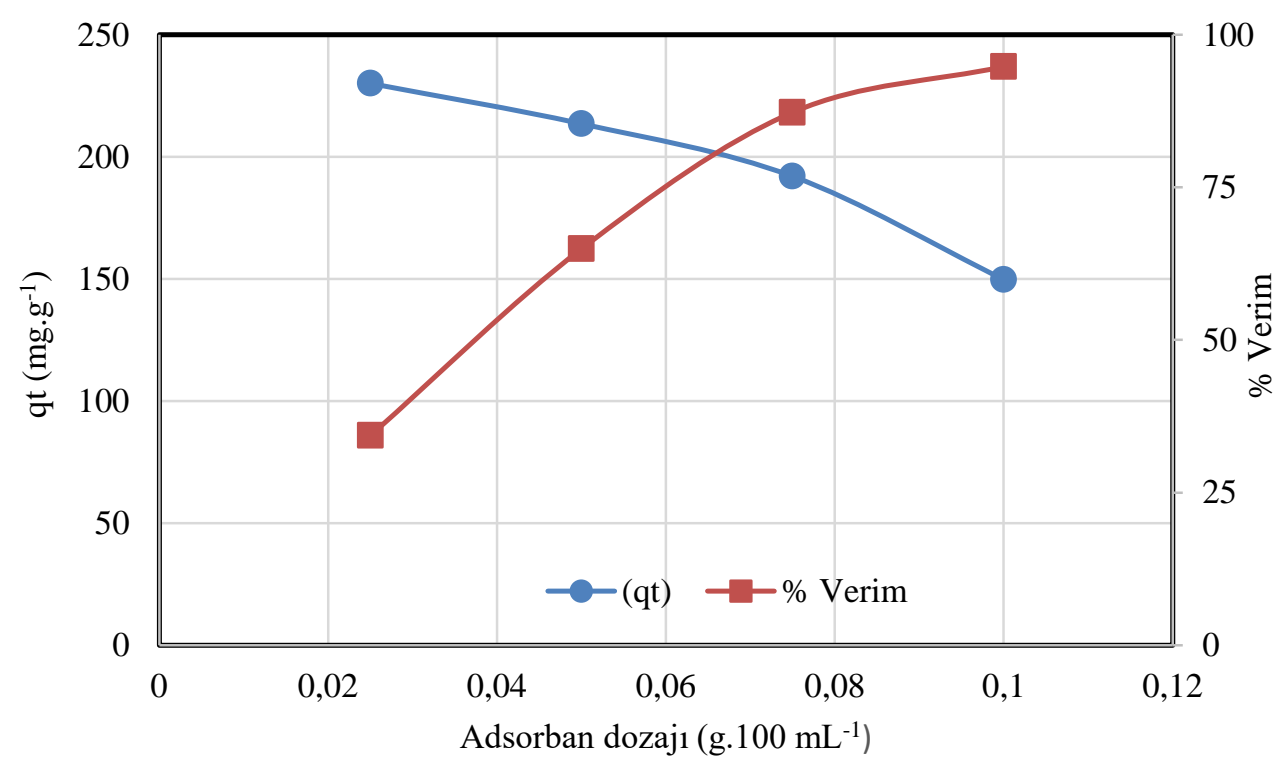

Şekil 5. Adsorpsiyon verimi üzerine adsorban dozajının etkisi

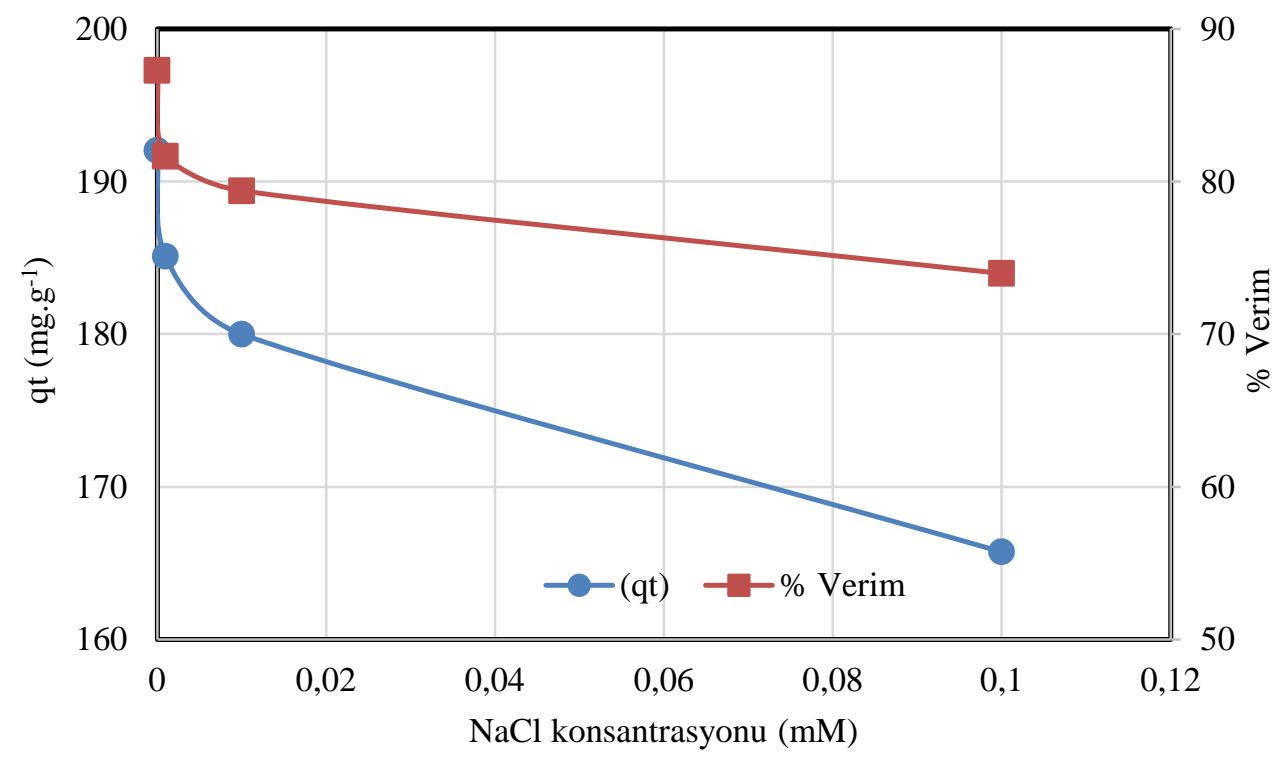

Şekil 6. Adsorpsiyon verimi üzerine $\mathrm{NaCl}$ konsantrasyonunun etkisi 
Deneysel sonuçlardan görüldüğü gibi $\mathrm{NaCl}$ konsantrasyonunun artmasiyla adsorpsiyon verimi azalmaktadır. $\mathrm{NaCl}$ konsantrasyonu 0 mM'den 0.1 mM'a arttığında adsorpsiyon kapasitesi 192.04 mg.g ${ }^{-1}$ den 165.73 mg.g ${ }^{-1}$ e ve KOİ giderim verimi de \%87.28'den \%73.98'e azalmıştır. İyonik şiddetteki artış adsorbat molekülleri ve adsorban yüzeyi arasındaki elektrostatik çekimi azaltır ve böylece adsorpsiyon kapasitesi azalır. $\mathrm{Bu}$ yüzden, doğal kil yüzeyindeki adsorpsiyon kapasitesi azalmaktadır (Dogan vd., 2009; Weng vd., 2009).

\section{Sonuçlar}

$\mathrm{Bu}$ çalışmada Erzurum ili Narman ilçesi havzasından temin edilmiş doğal sarı kil minerali ile tekstil endüstrisinde yaygın olarak kullanılan katyonik yapıda olan MM sulu çözeltilerinde KOİ adsorpsiyonu araştırılmıştır. Çalışmalar sonucunda doğal kil yüzeyinde birim adsorban başına adsorplanan KOİ miktarının, artan sulu çözelti pH'sı, karıştırma hızı ve başlangıç boyar madde konsantrasyonu ile arttığ1, artan adsorban dozajı ve $\mathrm{NaCl}$ konsantrasyonu ile azaldığ tespit edilmiştir. Denge anlarında maksimum adsorpsiyon verimleri $\mathrm{pH} 8.0$ ' de $200.20 \mathrm{mg} . \mathrm{g}^{-1}$, 400 dev.dak. ${ }^{-1}$ karıştırma hızında 191.375 mg.g.$^{-1}$, $500 \mathrm{mg} . \mathrm{L}^{-1}$ başlangıç $\mathrm{MM}$ konsantrasyonunda $338.13 \mathrm{mg} \cdot \mathrm{g}^{-1}$ ve $0.025 \mathrm{~g} .100 \mathrm{~mL}^{-1}$ adsorban dozajında $230.08 \mathrm{mg} . \mathrm{g}^{-1}$ olarak elde edilmiştir. En yüksek KOİ giderim verimleri ise; $\mathrm{pH} 8.0$ 'de \%87.30; 300 dev.dak ${ }^{-1}$ karıştırma hızında \%86.6; $50 \mathrm{mg} . \mathrm{L}^{-1} \mathrm{MM}$ konsantrasyonda \% 89.2; 0.1 g. $\mathrm{L}^{-1}$ adsorban dozajında \%94.79 ve elektrolit ilave yapılmadan gerçekleştirilen denemede \%87.28 olarak gerçekleşmiştir. Elde edilen adsorpsiyon kapasiteleri literatürdeki diğer çalışmalarla karşılaştırıldığında, doğal kilin birçok adsorbandan daha yüksek performans gösterdiği görülmüştür.

\section{Teşekkür}

$\mathrm{Bu}$ çalışmada, kil minerallerinin teminin edilmesinde katkılarından dolayı Sayın Prof. Dr. Suat AKBULUT ve Sayın Yrd. Doç. Dr. Zeynep Neşe KURT'a teşekkür ederim.

\section{Kaynaklar}

Almeida, C.A.P., Debacher, N.A., Downs, A.J., Cottet, L. ve Mello, C.A.D., 2009. Removal of Methylene Blue from Colored Effluents by Adsorption on Montmorillonite Clay. Journal of Colloid Interface Science, 332, 46-53.
Aoudj, S., Khelifa, A., Drouiche, N., Hecini, M. ve Hamitouche, H., 2010. Electrocoagulation Process Applied to Wastewater Containing Dyes from Textile Industry. Chemical Engineering and Processing: Process Intensification, 49, 1176-1182.

Apha, 1998. Standard Methods for the Examination of Water and Wastewater, 20th ed. AWWA.

Bangash, F.K. ve Alam, S., 2009. Adsorption of Acid Blue 1 on Activated Carbon Produced from the Wood of Ailanthus Altissima. Brazilian Journal of Chemical Engineering, $26,2,275-285$.

Bulut, E., Özacar, M. ve Şengil, İ.A., 2008. Adsorption of Malachite Green onto Bentonite: Equilibrium and Kinetic Studies and Process Design. Microporous and Mesoporous Material, 115, 234-246.

Crini, G., Peindy, H.N., Gimbert, F. ve Robert, C., 2007. Removal of CI Basic Green 4 (Malachite Green) from Aqueous Solutions by Adsorption Using Cyclodextrin-Based Adsorbent: Kinetic and Equilibrium Studies. Separation and Purification Technology, 53, 97-110.

Çulcu, L., 2015. Tekstil Endüstrisinde Kullanılan Asit Mavisi 62 Boyar Maddesinin Çapraz Bağlı Kitosan Üzerine Adsorpsiyonunun İncelenmesi, Yüksek Lisans Tezi, Yildız Teknik Üniversitesi, Fen Bilimleri Enstitüsü, İstanbul, 88s.

Doğan, M., Karaoğlu, M.H. ve Alkan, M., 2009. Adsorption Kinetics of Maxilon Yellow 4GL and Maxilon Red GRL Dyes on Kaolinite. Journal of Hazardous Materials, $165,1142-1151$

Gao, W., Zhao, S., Wu, H., Deligeer, W. ve Asuha, S., 2016. Direct Acid Activation of Kaolinite and Itts Effects on the Adsorption of Methylene Blue. Applied Clay Science. 126, 98-106

Gündoğdu，A. 2010. Çay Atıklarından Aktif Karbon Üretimi, Karakterizasyonu ve Adsorpsiyon Özelliklerinin İncelenmesi, Doktora Tezi, Karadeniz Teknik Üniversitesi, Fen Bilimleri Enstitüsü, Trabzon, 217s. 
Gürses, A., Doğar, C., Yalçın, M., Açıkyıldız, M., Bayrak, R. ve Karaca, S., 2006. The Adsorption Kinetics of the Cationic Dye Methylene Blue onto Clay. Journal of Hazardous Material B, 131, 217-228.

Habte, H., Zewge, F., ve Redi, M., 2014. Removal of Azo Dye from Water by Adsorption Using Waste Residue from Alum Manufacturing Process. African Journal of Environmental Science and Technology, 8(9), 482-490.

Han, R., Zhang, J., Han, P., Wang, Y., Zhao, Z. ve Tang, M., 2009. Study of Equilibrium, Kinetic and Thermodynamic Parameters about Methylene Blue Adsorption onto Natural Zeolite. Chemical Engineering Journal, 145, 496-504

Khaled, A., El Nemr, A., El-Sikaily, A. ve Abdelwahab, O., 2009. Removal of Direct N Blue-106 from Artificial Textile Dye Effluent Using Activated Carbon from Orange Peel: Adsorption İsotherm and Kinetic Studies. Journal of Hazardous Materials, 165, 100-110.

Kim, H. ve Guiochon, G., 2005. Adsorption on Molecularly İmprinted Polymers of Structural Analogues of a Template. SingleComponent Adsorption İsotherm Data. Analytical Chemistry, 77, 6415-6425.

Krishnan, K.A., Ajmal, K., Faisal, A.K. ve Liji, T.M., 2015. Kinetic And İsotherm Modeling Of Methylene Blue Adsorption Onto Kaolinite Clay At The Solid-Liquid Interface. Separation Science and Technology, 50, 1147-1157.

Kumar, K.V. ve Porkodi, K., 2006. Relation between Some Two- and Three-Parameter İsotherm Models for the Sorption of Methylene Blue onto Lemon Peel, Journal of Hazardous Material. 138, 633-635.

Kumar, K.V., Ramamurthi, V. ve Sivanesan, S., 2005. Modeling the Mechanism Involved during the Sorption of Methylene Blue onto Fly Ash. Journal of Colloid Interface Science, 284, 14-21.

Mahmoodi, N.M., 2011. Equilibrium, Kinetics, and Thermodynamics of Dye Removal Using Alginate in Binary Systems. Journal of Chemical and Engineering Data, 56, 2802-2811.

Man, L.W., Kumar, P., Teng, T.T. ve Wasewar, K.L., 2012. Design of Experiments for Malachite Green Dye Removal from Wastewater Using ThermolysisCoagulation-Flocculation. Desalination and Water Treatment, 40, 260-271

Moghaddam, S.S., Alavi Moghaddam, M.R., ve Arami, M., 2010. Coagulation/Flocculation Process for Dye Removal Using Sludge from Water Treatment Plant: Optimization through Response Surface Methodology. Journal of Hazardous Materials ,175(1-3), 651-657.

Molinari, R., Pirillo, F., Falco, M., Loddo, V. ve Palmisano, L., 2004. Photocatalytic Degradation of Dyes by Using a Membrane Reactor. Chemical Engineering and Processing: Process Intensification, 43, 1103-1114.

Mounia, L., Belkhiri, L., Bollinger, J.C., Bouzaza, A., Assadi, A., Tirri, A., Dahmoune F., Madani, K., ve Remini, H., 2018. Removal of Methylene Blue from Aqueous Solutions by Adsorption on Kaolin: Kinetic and Equilibrium Studies. Applied Clay Science, $153,38-45$.

Özdeş, D., Duran, C., Şentürk, H.B., Avan, H ve Burçin, B., 2009. Kinetics, Thermodynamics, and Equilibrium Evaluation of Adsorptive Removal of Methylene Blue onto Natural İlitic Clay Mineral. Desalination and Water Treatment, 52, (1-3), 208-218.

Özdeş, D., Gündoğdu, A., Bulut, V.N., Duran, C., ve Şentürk, H.B., 2009. Rodamin 6G Boyar maddesinin Pirinç Kabukları Üzerine Adsorpsiyonu. Dumlupınar Üniversitesi Fen Bilimleri Enstitü Dergisi, 20, 19-30.

Panizza, M ve Cerisola, G., 2009. Direct and Mediated Anodic Oxidation of Organic Pollutants. Chemical Review, 109,12, 6541-6569.

Sapawe, N., Jalil, A.A., Triwahyono, S., Shah, M.I.A., Jusoh, R., Salleh, N.F.M., Hameed, B.H. ve Karim, A.H., 2013. Cost-Effective Microwave Rapid Synthesis of Zeolite Naa 
for Removal of Methylene Blue. Chemical Engineering Journal. 229, 388-398.

Schimmel, D., Fagnani, K.C., Oliveira dos Santos. J.B., Barros, M.A.S.D. ve Antonio da Silva, E., 2010. Adsorption of Turquoise Blue QG Reactive by Commercial Activated Carbon in Batch Reactor: Kinetic and Equilibrium Studies. Brazilian Journal of Chemical Engineering, 27, 289-298.

Somasekhara Reddy, M.C., Sivaramakrishna, L. ve Varada Reddy, A., 2012. The Use of an Agricultural Waste Material, Jujuba Seeds for the Removal of Anionic Dye (Congo Red) from Aqueous Medium. Journal of Hazardous Materials, 203-204, 118-127.

Sözüdoğru, O., Fil, B.A., Boncukcuoğlu, R., Aladağ, E., ve Kul, S., 2016. Adsorptive Removal of Cationic (BY2) Dye from Aqueous Solutions onto Turkish Clay. Particulate Science and Technology, 34,1, 103-111.

Uzuner, B.A., 2005. Temel Zemin Mekaniği, Teknik Yayınevi, Trabzon, 485s.

Vadivelan, V. ve Kumar, K. V., 2005. Equilibrium, Kinetics, Mechanism, and Process Design for the Sorption of Methylene Blue onto Rice Husk. Journal of Colloid Interface Science, 286, 90-100.

Van Leeuwen, J., Sridhar, A., Esplugas, M., Onuki, S., Cai, L. ve Koziel, J.A., 2009. Ozonation within an Activated Sludge System for Azo Dye Removal by Partial Oxidation and Biodegradation. Ozone: Science \& Engineering, 31, 279-286.

Varlikli, C., Bekiari, V., Kus, M., Boduroglu, N., Oner, I., Lianos, P., Lyberatos, G. ve Icli, S., 2009. Adsorption of Dyes on Sahara Desert Sand. Journal of Hazardous Materials, 170, 27-34.
Veli, S. ve Alyüz, B., 2007. Adsorption of Copper And Zinc From Aqueous Solutions by Using Natural Clay. Journal of Hazardous Materials, 149, 226-233.

Veliev, E.V., Öztürk, T., Veli, S. ve Fatullayev, A.G., 2006. Application of Diffusion Model for Adsorption of Azo Reactive Dye on Pumice. Polish Journal of Environmental Studies, 15, 347-353.

Vimonses, V., Lei, S., Jin, B., Chow, C.W.K. ve Saint, C., 2009. Kinetic Study and Equilibrium İsotherm Analysis of Congo Red Adsorption by Clay Materials. Chemical Engineering Journal, 148, 354364.

Vučurović, V.M., Razmovski, R.N. ve Tekić, M.N., 2012. Methylene Blue (Cationic Dye) Adsorption onto Sugar Beet Pulp: Equilibrium İsotherm and Kinetic Studies. Journal of the Taiwan Institute of Chemical Engineers, 43, 108-111.

Weng, C.H., Lin, Y.T. ve Tzeng, T.W., 2009. Removal of Methylene Blue from Aqueous Solution by Adsorption onto Pineapple Leaf Powder. Journal of Hazardous Materials, 170, 417-424.

Yılmaz, Y.A. 2009. Bask1 Boyama Atıksularının İnert KOİ Bilesenlerine Fenton Prosesinin Etkisi, Cumhuriyet Üniversitesi, Fen Bilimleri Enstitüsü, Sivas, 97s.

Yilmaz, A.E., 2012. Determination of the optimum Conditions in the Removal of Color From Synthetic Textile Wastewater Using Electrocoagulation Method. Fresenius Environmental Bulletin, 21 (5), 1052-1059.

Zhu, X., Zheng, Y., Chen, Z., Chen, Q., Gao, B. ve Yu, S., 2013. Removal of Reactive Dye From Textile Effluent through Submerged Filtration Using Hollow Fiber Composite Nanofiltration Membrane. Desalination and Water Treatment, 51 (31-33), 6101-6109. 